\title{
3,3',5,5'-tetramethylbenzidine as multi-colorimetric indicator of chlorine in water in line with health guideline values
}

\author{
Pasquale Palladino $^{1} \cdot$ Francesca Torrini $^{1} \cdot$ Simona Scarano $^{1} \cdot$ Maria Minunni $^{1}$ \\ Received: 15 July 2020 / Revised: 7 August 2020 / Accepted: 25 August 2020 / Published online: 1 September 2020 \\ (C) Springer-Verlag GmbH Germany, part of Springer Nature 2020
}

\begin{abstract}
Sanitizing solutions against bacterial and viral pathogens are of utmost importance in general and, in particular, in these times of pandemic due to Sars-Cov2. They frequently consist of chlorine-based solutions, or in the direct input of a certain amount of chlorine in water supply systems and swimming pools. Colorimetry is one of the techniques used to measure the crucial persistence of chlorine in water, including household chlorine test kits commonly based on colorimetric indicators. Here, we show a simple and cheap colorimetric method based on 3,3',5,5'-tetramethylbenzidine (TMB), commonly used as chromogenic reagent for enzyme-linked immunosorbent assays. TMB is converted by chlorine to a colored molecule through a pH-dependent multi-step oxidation process where the chromaticity of TMB is directly proportional to chlorine content. This molecule offers several advantages over other commonly used reagents in terms of safety, sensitivity, and, peculiarly, hue modulation, giving rise to the detection of chlorine in water with a multi-color change of the indicator solution (transparent/blue/green/yellow). Moreover, through the appropriate setting of reaction conditions, such coloration is finely tunable to cover the range of chlorine concentration recommended by international health agencies for treatment of drinking water and swimming pools and to test homemade solutions prepared by dilution of household bleach during health emergency events such as during the current pandemic.
\end{abstract}

Keywords 3,3',5,5'-tetramethylbenzidine (TMB) - Multi-color indicator · Naked-eye sensing $\cdot$ Chlorine $\cdot$ Water treatment . Sanitizing solution

$\begin{array}{ll}\text { Abbreviations } \\ \text { TMB } & 3,3^{\prime}, 5,5^{\prime} \text {-Tetramethylbenzidine } \\ \text { HRP } & \text { Horseradish peroxidase } \\ \text { DPD } & \text { N,N-Diethyl-p-phenylenediamine } \\ \text { OTO } & o \text {-Tolidine } \\ \text { EPA } & \text { United States Environmental Protection Agency } \\ \text { WHO } & \text { World Health Organization } \\ \text { ELISA } & \text { Enzyme-linked immunosorbent assay }\end{array}$

Electronic supplementary material The online version of this article (https://doi.org/10.1007/s00216-020-02918-9) contains supplementary material, which is available to authorized users.

Pasquale Palladino

pasquale.palladino@unifi.it

1 Department of Chemistry 'Ugo Schiff', University of Florence, Via della Lastruccia 3-13, 50019 Sesto Fiorentino, Italy

\section{Introduction}

Chlorine and chlorine-based compounds are widely used for oxidative inactivation of several disease-causing viruses and bacteria in water treatments, for food preservation, and during other cleaning procedures $[1,2]$. In all cases, the presence of chlorine residual is required to ensure the protection from recontamination. The range of chlorine concentrations recommended by international health or environmental agencies depends on the application, spanning several orders of magnitude from drinking water to sanitizing or disinfecting solutions. In detail, chlorine can be added to drinking water or swimming pools to achieve a minimum level of $0.2-$ $0.5 \mathrm{mg} \mathrm{L}^{-1}$ (expressed as $\mathrm{Cl}_{2}$ ) for effective disinfection and residual concentration but should stay below $4-5 \mathrm{mg} \mathrm{L}^{-1}$ to avoid eye/nose irritation and stomach discomfort [3, 4], whereas sanitizing solutions applied to reduce germs for example on food contact surfaces or mouthed toys are obtained by dilution of concentrated chlorine bleach to $50-200 \mathrm{mg} \mathrm{L}^{-1}$. Finally, disinfecting concentration for toilet or diapering areas 
should be larger than $2400 \mathrm{mg} \mathrm{L}^{-1}$. The standard analytical methods for the determination of chlorine in natural and treated waters are based on electrochemical techniques, iodometry, and absorption spectrophotometry [5-10], usually requiring devices for signal transduction or UV lamp for fluorescence emission. However, several kits for household chlorine test are present in the market for colorimetric quantification of chlorine concentration based on monochromatic indicators. Here, we introduce a peculiar use of $3,3^{\prime}, 5,5^{\prime}$ tetramethylbenzidine (TMB) as multi-colorimetric indicator for determination of chlorine in aqueous solution. TMB is still one of the most commonly used chromogenic reagents for enzyme-linked immunosorbent assays (ELISAs) 46 years after its first synthesis as a safer substitute for carcinogenic benzidine in the detection of occult blood [11-14]. This molecule gives rise to non-colored solution in a reduced state that becomes blue upon oxidation (diamine). Further oxidation leads to a green stage, which is a mixture of the blue stage and the yellow endpoint (diimine). Notably, the blue-colored product has been characterized as the diamine/diimine charge-transfer complex in equilibrium with the cation-radical and diamine/ diamine mixture, as reported in Fig. 1 [15, 16]. This reaction sequence is sensitive to several factors, like $\mathrm{pH}$ [16], solvent, temperature [17, 18], and catalyst [14, 19, 20]. The application of TMB as an analytical reagent outside the field of clinical chemistry started a long time ago thanks to good stability of the reaction product and high sensitivity and selectivity of such analytical methods [21-24]. Notably, thanks to ionmasking salts, TMB-based assays, either based on the detection of yellow diamine or blue diamine/diimine chargetransfer complex, have shown a high tolerance for potential interfering species in drinking water (including $\mathrm{Cl}^{-}, \mathrm{I}^{-}, \mathrm{NO}_{3}{ }^{-}$, $\mathrm{SO}_{4}{ }^{2-}, \mathrm{CO}_{3}{ }^{2-}, \mathrm{H}_{2} \mathrm{PO}_{4}{ }^{-}, \mathrm{P}_{2} \mathrm{O}_{7}{ }^{4-}, \mathrm{Na}^{+}, \mathrm{K}^{+}, \mathrm{Mg}^{2+}, \mathrm{Ca}^{2+}, \mathrm{Zn}^{2+}$, $\mathrm{Fe}^{3+}$, and $\mathrm{H}_{2} \mathrm{O}_{2}$ ) being the common and permitted concentrations of these molecules below the respective limits of interference elsewhere described (see Table S1 in Electronic Supplementary Material, ESM) [21-24]. Consequently, the reactions reported in Fig. 1 have been used for quantitative measurements of chlorine in water [21-25], under organic matter-rich conditions [26], or generated by myeloperoxidase of neutrophils [27-29], reaching an enhanced degree of automation and reduced reagent consumption and waste production [23]. All the species reported in Fig.1, obtained in water and other solvents, by enzymatic, chemical, or electrochemical oxidation, have been detected and characterized elsewhere by optical spectroscopy, electron spin resonance spectroscopy, and resonance Raman scattering spectroscopy [15, 16, 18, $19,24,25]$. Although a rigorous control of $\mathrm{pH}$ is not necessary, the $\mathrm{pH}$ range determines the color development. In detail, $\mathrm{pH}$ 1-2 allows to follow the yellow TMB-diimine formation only (Fig. 1C) [21-23, 25], whereas pH 4-6 has been used to track the blue TMB charge-transfer complex formation (Fig. 1B) [24]. In both conditions, the color intensity is directly proportional to the total amount of the chlorine present in the solution, reporting a limit of detection as low as $2 \mu \mathrm{g} \mathrm{L}^{-1}$ at $\mathrm{pH} 1.5$ and $4 \mu \mathrm{g} \mathrm{L}{ }^{-1}$ at $\mathrm{pH} 4.5$ [22]. TMB presents several advantages in terms of sensitivity, selectivity and safety over the other reagents used for colorimetric analysis of

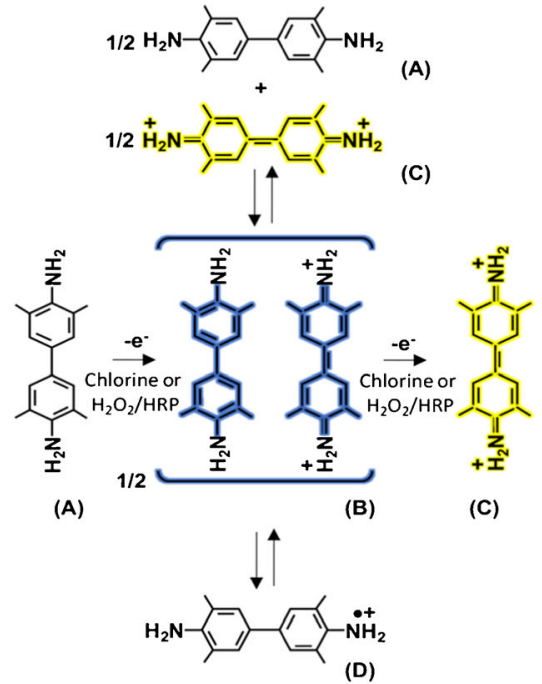

Fig. 1 The reaction sequence of TMB oxidation by chlorine (this work) $[24,25]$, or by $\mathrm{H}_{2} \mathrm{O}_{2}$ in presence of peroxidase catalyst (HRP) $[15,16,18$, 19], as elsewhere identified by means of optical spectroscopy, electron spin resonance spectroscopy, and resonance Raman scattering spectroscopy $[15,16,18,19,24,25]$. A Non-colored reduced state (diamine). B

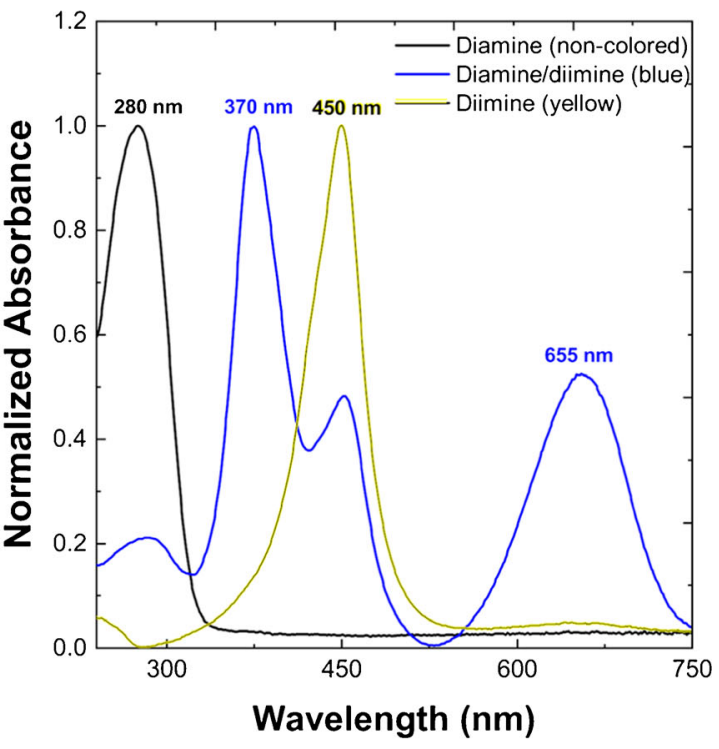

Blue charge-transfer complex (diamine/diimine). C Yellow two-electron oxidation product (diimine). D One-electron oxidation product (cationradical). The most representative UV-Vis spectra for the TMB species upon oxidation by chlorine (this work) are reported on the right 
chlorine in water like $o$-tolidine (OTO), syringaldazine, N,Ndiethyl-p-phenylenediamine (DPD), and dopamine $[9,10,21$, $22,30]$. Here, we report the experimental tuning of TMB concentration, according to one-to-one stoichiometry for oxidant/substrate system [15], to achieve the visual and spectroscopic detection of chlorine by means of the color change of the solution from blue to yellow (Fig. 1) like a universal indicator that covers the entire range of chlorine concentrations recommended for drinking water and swimming pool treatment $[3,4]$. This method appears superior to common household chlorine test kits for drinking water and swimming pools, which are based on monochromatic indicators, and could offer a useful tool to check home-made chlorine-based sanitizing solutions, which become rare during public health emergency events due to large demand.

\section{Materials and method}

\section{Reagents and materials}

Disposable low-binding 96 microplates were purchased from Sarstedt (Germany). Absorption suprasil® quartz cuvettes of $10-\mathrm{mm}$ pathlength and $1400-\mu \mathrm{L}$ chamber volume were provided by Hellma GmbH \& Co. KG (Germany). Sodium hypochlorite solution was purchased from Merck KGaA (Germany) (Lot number: K50436114, originally containing $120 \mathrm{~g} \mathrm{~L}^{-1}$ of active chlorine as calculated from iodometric titration) and used to prepare stock solutions based on the intrinsic UV absorbance of $\mathrm{ClO}^{-}$[31]. DPD1 free chlorine test kit was purchased from Powehaus24® GmbH \& Co. KG (Germany). TMB and other chemicals were purchased from Sigma Aldrich (Milan, Italy). A stock solution of about $1 \mathrm{mM}$ TMB has been prepared in ethanol $/ \mathrm{H}_{2} \mathrm{O} 1: 1 \mathrm{v} / \mathrm{v}$ and left overnight at room temperature (RT) until completely dissolved before storing it at $4{ }^{\circ} \mathrm{C}$ in a dark bottle. All reagents were used as received without any further purification. MilliQ water with a resistivity of $18.2 \mathrm{M} \Omega \mathrm{cm}$ at $25.0{ }^{\circ} \mathrm{C}$ was degassed and used in preparation of all the solutions (Merck Millipore, Italy).

\section{UV-Vis spectroscopy}

Optical measurements have been performed on a UV-visible spectrophotometer Evolution 201 from Thermo Scientific at $25.0^{\circ} \mathrm{C}$, by using quartz cells also for determination of hypochlorite concentration of the stock solution, and on a microplate absorbance visible reader iMark $^{\mathrm{TM}}$ from Bio-Rad at room temperature, by using 96-well polystyrene microplates. Acetic acid/sodium acetate $200.0 \mathrm{mM}$ in the presence of tetrasodium diphosphate $40.0 \mathrm{mM}\left(\mathrm{Na}_{4} \mathrm{P}_{2} \mathrm{O}_{7}\right)$, referred to hereinafter as buffer 1 , or disodium dihydrogen diphosphate $20.0 \mathrm{mM}\left(\mathrm{Na}_{2} \mathrm{H}_{2} \mathrm{P}_{2} \mathrm{O}_{7}\right)$, referred to hereinafter as buffer 2, have been chosen to stabilize TMB solution around $\mathrm{pH} 4.5$. Spectrophotometric measurements have been carried out by filling the quartz cuvette with $700 \mu \mathrm{L}$ of TMB $42.3 \times 10^{-6} \mathrm{M}$ plus $700 \mu \mathrm{L}$ of freshly prepared $\mathrm{H}_{2} \mathrm{O}$ or tap water samples containing chlorine in the range $0.25-5.00 \mathrm{mg} \mathrm{L}^{-1}$ with three replicas for each chlorine concentration. After the analysis of each chlorine concentration, the cuvette has been emptied and thoroughly washed. Analogously, microplate experiments have been performed adding $150 \mu \mathrm{L}$ of freshly prepared $\mathrm{H}_{2} \mathrm{O}$ or tap water samples to each well containing chlorine in the range $0.25-5.00 \mathrm{mg} \mathrm{L}^{-1}$ with 4 replicas for each chlorine concentration. All the wells have been preloaded with $150 \mu \mathrm{L}$ of $\mathrm{TMB} 42.3 \times 10^{-6} \mathrm{M}$, which is equimolar to $3.00 \mathrm{mg} \mathrm{L}^{-1}$ of active chlorine for drinking water or swimming pool simulation. Finally, a DPD1 chlorine test kit has been used following the manufacturer's instructions. Data were analyzed with OriginLab Corporation software.

\section{Results and discussion}

\section{Chlorine titration experiments}

Titration curve of TMB with $\mathrm{H}_{2} \mathrm{O}_{2}\left(50 \times 10^{-6} \mathrm{M}\right.$ at pH 5.0) in presence of horseradish peroxidase catalyst (HRP) has been elsewhere reported [15], showing that the blue charge-transfer complex formation and subsequent destruction is nearly symmetrical about the midpoint. The endpoint has been found to correspond to about equimolar peroxide and TMB, obtaining the full conversion to diimine and thus confirming a one-toone stoichiometry for this catalyzed TMB/oxidant reaction. Analogously, here we follow spectrophotometrically all the stages of reaction in Fig. 1 exploiting the full potential of the catalyst-free TMB reaction with active chlorine by titration, in polystyrene plates or quartz cuvettes, in a mild acidic buffer that controls chlorine speciation and TMB reactivity.

In detail, molecular chlorine $\left(\mathrm{Cl}_{2}\right)$ is mostly present at $\mathrm{pH}<$ 2 , hypochlorous acid $(\mathrm{HOCl})$ dominates the equilibrium at 4 $<\mathrm{pH}<6$, and hypochlorite $\left(\mathrm{ClO}^{-}\right)$is predominant at $\mathrm{pH}>8$ $[29,31]$. Buffering the sample solutions in one of these $\mathrm{pH}$ ranges can limit the variability of results due to different reactivity of chlorine species. However, a mild acidic buffer guarantees the best conditions to measure the chlorine content in real samples by tracking all the non-catalytic oxidation stages of TMB (Fig. 1). In fact, it has been demonstrated that a $\mathrm{pH}$ below 2 prevents the formation of the blue TMB chargetransfer complex formation (Fig. 1B) in favor of yellow TMB-diimine formation only (Fig. 1C). Analogously, it has been reported that the charge-transfer complex formation is significantly reduced at $\mathrm{pH}$ above 6 . Therefore, we have performed experiments stabilizing TMB solution at $\mathrm{pH} 4.5$ with diphosphate salts (see Materials and method), thus preventing interference from redox-active ions like Fe(III) potentially 
present in water supply systems, as elsewhere demonstrated by extensive interference studies [21-24]. Differently from previously reported single-color intensity estimation with TMB (either yellow or blue) or DPD (magenta) [21-26, 29], this method allows the naked-eye quantification of chlorine by multi-color changes of TMB solution. This approach for the first time proposes TMB as a universal indicator for the selected range of chlorine concentrations, from a minimum blue level for effective disinfection, through an optimal green level, up to the safe yellow guideline level corresponding to equimolar chlorine and TMB (see below).

\section{TMB reaction with active chlorine in $\mathrm{H}_{2} \mathrm{O}$ and tap water}

Figure 2a shows preliminary experiments of color development for TMB test solution in buffer 1 ( $\mathrm{pH} 4.5$, see "Materials and method") with chlorine samples in $\mathrm{H}_{2} \mathrm{O}$ in quartz cuvettes. The main representative absorbances selected from $\mathrm{UV}$-visible spectra at $25.0^{\circ} \mathrm{C}$ have been acquired in a kinetic rate mode and reported in Fig. 2b. In detail, after $30 \mathrm{~s}$ of incubation necessary for sample preparation, absorbances at three fixed wavelengths $(280 \mathrm{~nm}, 450 \mathrm{~nm}$ and $655 \mathrm{~nm}$ ) have been recorded every $10 \mathrm{~s}$ for a total accumulation time of $300 \mathrm{~s}$. The solution of a fixed amount of TMB $42.3 \times$ $10^{-6} \mathrm{M}$ is initially transparent due to UV absorbance only of diamine ( $\lambda_{\max } 280 \mathrm{~nm}$, Fig. 1A) that decreases along with chlorine accumulation (Fig. 2b). Simultaneously, the solution develops a blue color of increasing intensity in the presence of chlorine from 0.25 to $1.00 \mathrm{mg} \mathrm{L}^{-1}$. This visible band corresponds to the blue diamine/diimine charge-transfer complex ( $\lambda_{\max } 655 \mathrm{~nm}$, Fig. 1b). The titration curve at $655 \mathrm{~nm}$ shows the formation and subsequent disappearance of the blue product (Fig. 2b). Higher concentrations of chlorine lead to the appearance of green color, due to blue/yellow absorbance mixing. A yellow solution due to the yellow diimine form of $\operatorname{TMB}\left(\lambda_{\max } 450 \mathrm{~nm}\right.$, Fig. 1C) is obtained at higher chlorine concentration up to $3.00 \mathrm{mg} \mathrm{L}{ }^{-1}$ of $\mathrm{Cl}_{2}$. Finally, the solution becomes orange when chlorine reaches the $5.00 \mathrm{mg} \mathrm{L}^{-1}$ $\left(70.5 \times 10^{-6} \mathrm{M}\right)$, which is the guideline value that could lead to potential health effects from long-term exposure [3, 4]. Data show good reproducibility, obtaining a mean coefficient of variation of $4.72 \%$ for absorbance values at $280 \mathrm{~nm}, 3.91 \%$ at $450 \mathrm{~nm}$, and $3.52 \%$ at $655 \mathrm{~nm}$ over the entire range of chlorine concentrations after $0 \mathrm{~s}$, for example (Table 1). All the reactions appear complete within $1 \mathrm{~min}$ in agreement with previous observations of blue color development obtained in similar conditions but with a large excess of TMB [24]. The time evolution plots of main absorbance bands are reported in Fig. $2 \mathrm{c}$ showing quite stable colors at $25.0^{\circ} \mathrm{C}$. Similar results were obtained in buffer 2 ; however, absorbance values appear less stable after $15 \mathrm{~min}$ (data not shown). The same experiments performed by using tap water for chlorine dilutions instead of $\mathrm{H}_{2} \mathrm{O}$ have been reported in Fig. 3, showing a limited matrix effect (likely due to foreign ions) on color appearance and intensity along with chlorine titration with respect to $\mathrm{H}_{2} \mathrm{O}$ alone, confirming the good reproducibility, obtaining, for example, a mean coefficient of variation of $3.18 \%$ for absorbance values at $280 \mathrm{~nm}, 3.23 \%$ at $450 \mathrm{~nm}$, and $2.66 \%$ at $655 \mathrm{~nm}$ after $0 \mathrm{~s}$ (Table 1). The complete dataset for experiments in $\mathrm{H}_{2} \mathrm{O}$ or tap water, in dependence of time, chlorine concentration, and $\lambda_{\max }$, shown in Figs. 2, 3, and 4 is available as ESM.
Fig. 2 Reaction of TMB solution in buffer 1 ( $\mathrm{pH} 4.5$ ) with active chlorine in $\mathrm{H}_{2} \mathrm{O}$ at $25.0^{\circ} \mathrm{C}$. a Color development for TMB oxidation by chlorine in quartz cuvettes. b Absorbance at $280 \mathrm{~nm}, 450 \mathrm{~nm}$ and $655 \mathrm{~nm}$. c Time evolution plot for the TMB absorbance at different wavelengths after reaction with chlorine. The absorbances are reported as mean value of three replicates for each chlorine concentration
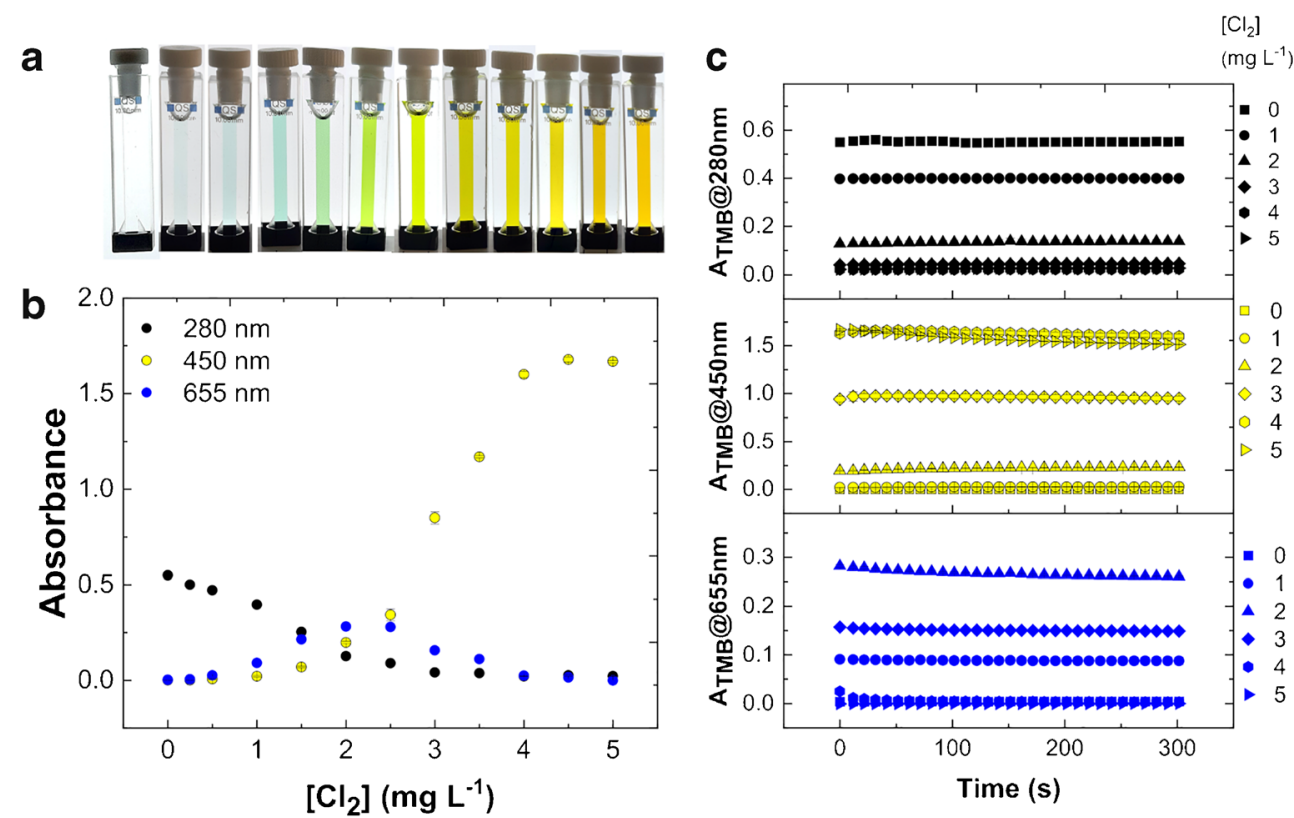
Table 1 Coefficient of variation $(\% \mathrm{CV})$ for Absorbance values vs $\left[\mathrm{Cl}_{2}\right]$ from Fig. $2\left(\mathrm{H}_{2} \mathrm{O}\right)$ and Fig. 3 (tap water)

\begin{tabular}{lccccccc}
\hline Time $0(\mathrm{~s})$ & \multicolumn{2}{l}{ Absorbance in $\mathrm{H}_{2} \mathrm{O}(\% \mathrm{CV})$} & & \multicolumn{3}{l}{ Absorbance in tap water $(\% \mathrm{CV})$} \\
\cline { 2 - 3 }$\left[\mathrm{Cl}_{2}\right] \mathrm{mg} \mathrm{L}^{-1}$ & $280 \mathrm{~nm}$ & $450 \mathrm{~nm}$ & $655 \mathrm{~nm}$ & & $280 \mathrm{~nm}$ & $450 \mathrm{~nm}$ & $655 \mathrm{~nm}$ \\
\hline 0.00 & 0.92 & 4.89 & 1.55 & & 0.29 & 8.25 & 1.06 \\
0.25 & 1.00 & 3.73 & 2.34 & & 3.51 & 0.50 & 7.58 \\
0.50 & 0.71 & 4.80 & 2.50 & & 0.88 & 3.11 & 4.23 \\
1.00 & 1.00 & 9.58 & 8.08 & & 2.02 & 4.16 & 4.72 \\
1.50 & 4.86 & 5.77 & 1.69 & & 1.11 & 9.99 & 3.93 \\
2.00 & 6.02 & 2.86 & 1.06 & & 5.03 & 0.69 & 2.69 \\
2.50 & 1.72 & 9.18 & 1.07 & & 0.47 & 0.77 & 0.62 \\
3.00 & 14.5 & 3.35 & 1.91 & & 1.27 & 2.51 & 0.05 \\
3.50 & 2.37 & 0.49 & 2.70 & & 1.07 & 2.58 & 1.98 \\
4.00 & 1.44 & 1.00 & 3.39 & & 5.85 & 3.15 & 1.39 \\
4.50 & 15.9 & 0.77 & 5.60 & & 13.8 & 2.42 & 3.31 \\
5.00 & 6.17 & 0.54 & 10.3 & & 2.87 & 0.60 & 0.30 \\
\% & $\mathbf{4 . 7 2}$ & $\mathbf{3 . 9 1}$ & $\mathbf{3 . 5 2}$ & $\mathbf{3 . 1 8}$ & $\mathbf{3 . 2 3}$ & $\mathbf{2 . 6 6}$ \\
\hline
\end{tabular}

\section{Comparison of TMB method with a DPD1 chlorine test kit}

96-well polystyrene microplates have been used for the optimization of the method, enabling the experimental procedure described for quartz cuvettes to be carried out on 96 samples simultaneously, with minor volume consumption and thus more replicates for each chlorine concentration. Furthermore, taking the advantage of distinct visible $\lambda_{\max } \mathrm{ab}$ sorbances for TMB oxidation products by reaction with chlorine, we have used a filter-based plate reader instead of a spectrophotometer preliminarily used for greater flexibility due to wavelength scanning capability from UV to visible.
In detail, DPD-containing tablets from a commercial test kit have been compared with the TMB solution in buffer 1 here formulated for the naked-eye sensing of chlorine concentration in water samples. Figure 4a shows a polystyrene microplate containing $\mathrm{Cl}_{2}$ in $\mathrm{H}_{2} \mathrm{O}$, including the range of concentrations recommended for drinking water treatment, about $0.25-3.00 \mathrm{mg} \mathrm{L}^{-1}[3,4]$, in presence of a fixed amount of DPD or TMB. DPD solutions have been prepared mimicking a swimming pool test; i.e., using one DPD tablet for $13 \mathrm{~mL}$ of water, which is the volume of the commercial test tube. Such chlorine solutions present a magenta color with intensity depending on chlorine content and here ideally representing the color reference scale for a chlorine sample test with DPD.
Fig. 3 Reaction of TMB solution in buffer 1 ( $\mathrm{pH} 4.5$ ) with active chlorine in tap water at $25.0^{\circ} \mathrm{C}$. a Color development for TMB oxidation by chlorine in quartz cuvettes. b Absorbance at $280 \mathrm{~nm}, 450 \mathrm{~nm}$, and $655 \mathrm{~nm}$. c Time evolution plot for the TMB absorbance at different wavelengths after reaction with chlorine. The absorbances are reported as mean value of three replicates for each chlorine concentration

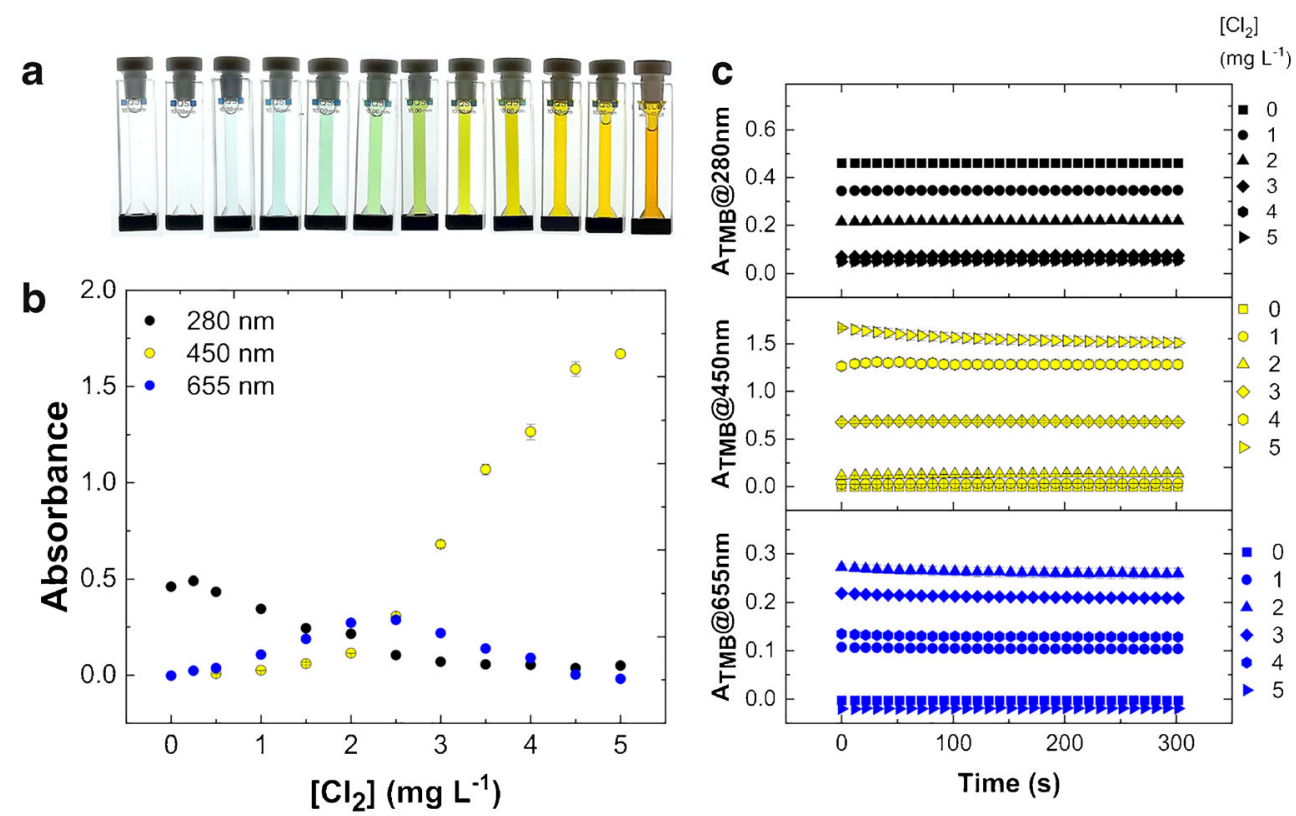


Fig. 4 TMB prepared in buffer 1 versus DPD test kit for chlorine detection by microplate visible reader. Chlorine concentration ranges from 0.25 to $5.00 \mathrm{mg} \mathrm{L}^{-1}$ with four replicas for each chlorine solution in $\mathrm{H}_{2} \mathrm{O}$ (a) or tap water (b). Each well of a 96-well polystyrene microplate contains $300 \mu \mathrm{L}$ of sample solution with a final concentration of 1 tablet of DPD for $13 \mathrm{~mL}$ of water, as required by original commercial test, or TMB equimolar to $3.00 \mathrm{mg} \mathrm{L}^{-1}$ of $\mathrm{Cl}_{2}$ in buffer. The absorbances at $450 \mathrm{~nm}$ and $655 \mathrm{~nm}$ (TMB), and $555 \mathrm{~nm}$ (DPD) for chlorine in $\mathrm{H}_{2} \mathrm{O}$ (c) or tap water (d) are reported as mean value of four replicates for each chlorine concentration a

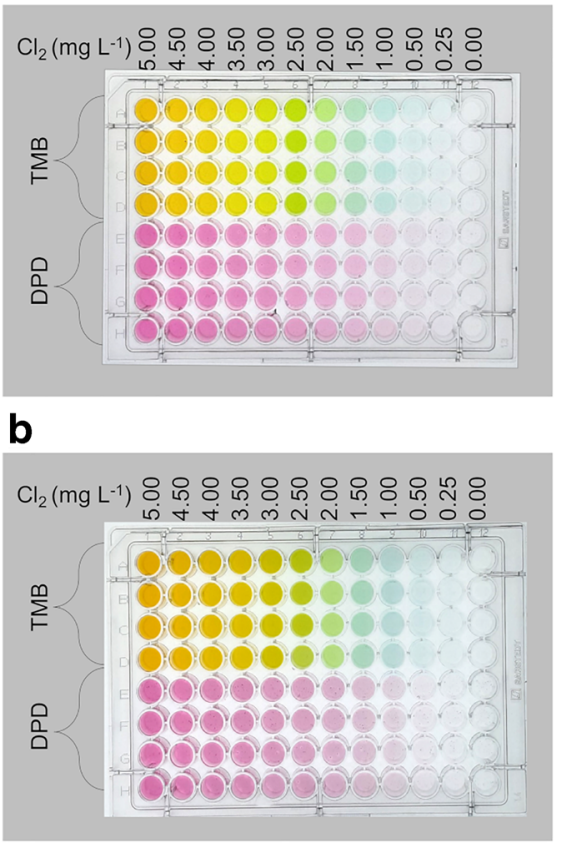

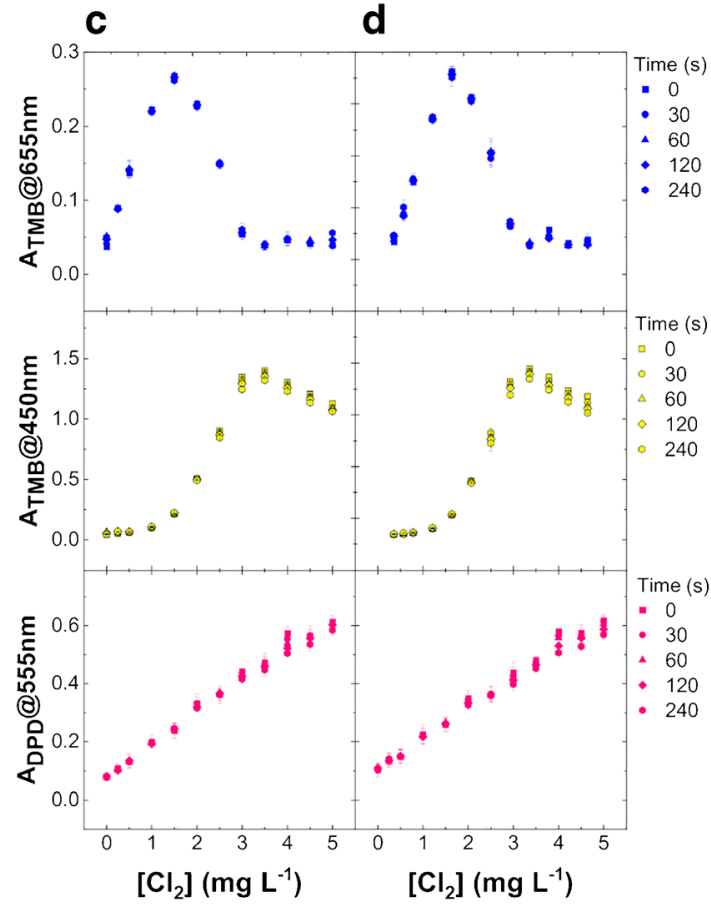

However, it seems difficult to distinguish the analyte concentration solely by naked-eye comparison of color intensities. On the contrary, the same chlorine solutions give different colors in presence of TMB, from light blue to bright yellow through green hues, depicting the color reference scale for a chlorine test with this TMB formulation, which allows an easier visual sensing and estimation of chlorine content, behaving like a universal indicator within the chosen range of chlorine concentration. The same results have been obtained by using tap water for chlorine dilutions (Fig. 4b). The representative absorbances of the main molecular species and colors are reported in Fig. $4 \mathrm{c}$ and $\mathrm{d}$ for $\mathrm{H}_{2} \mathrm{O}$ and tap water solutions, respectively. As expected, the absorbances of TMB solution recorded at $450 \mathrm{~nm}$ (yellow) and $655 \mathrm{~nm}$ (blue) follow the trend observed in quartz cuvettes with optimal results in terms of reproducibility expressed as percent coefficient of variation (\% CV in Table 2). In particular, the titration curve at $655 \mathrm{~nm}$ shows the formation and subsequent disappearance of
Table 2 Coefficient of variation $(\% \mathrm{CV})$ for Absorbance values vs $\left[\mathrm{Cl}_{2}\right]$ from Fig. $4 \mathrm{c}\left(\mathrm{H}_{2} \mathrm{O}\right)$ and Fig. $4 \mathrm{~d}$ (tap water)

\begin{tabular}{|c|c|c|c|c|c|c|}
\hline \multirow{3}{*}{$\begin{array}{l}\text { Time } 0(\mathrm{~s}) \\
{\left[\mathrm{Cl}_{2}\right] \mathrm{mg} \mathrm{L}^{-1}}\end{array}$} & \multicolumn{3}{|c|}{ Absorbance in $\mathrm{H}_{2} \mathrm{O}(\% \mathrm{CV})$} & \multicolumn{3}{|c|}{ Absorbance in Tap water (\%CV) } \\
\hline & \multirow{2}{*}{$\begin{array}{l}\text { DPD } \\
555 \mathrm{~nm}\end{array}$} & \multicolumn{2}{|l|}{ TMB } & \multirow{2}{*}{$\begin{array}{l}\text { DPD } \\
555 \mathrm{~nm}\end{array}$} & \multicolumn{2}{|l|}{ TMB } \\
\hline & & $450 \mathrm{~nm}$ & $655 \mathrm{~nm}$ & & $450 \mathrm{~nm}$ & $655 \mathrm{~nm}$ \\
\hline 0.00 & 5.89 & 5.29 & 5.41 & 14.7 & 7.64 & 2.56 \\
\hline 0.25 & 11.0 & 17.9 & 1.11 & 16.9 & 17.5 & 6.54 \\
\hline 0.50 & 18.4 & 6.05 & 4.07 & 16.2 & 9.79 & 1.78 \\
\hline 1.00 & 11.1 & 10.7 & 2.66 & 15.3 & 9.43 & 1.57 \\
\hline 1.50 & 10.9 & 0.48 & 0.71 & 10.2 & 3.77 & 2.53 \\
\hline 2.00 & 8.86 & 0.81 & 1.83 & 7.94 & 2.21 & 1.45 \\
\hline 2.50 & 8.19 & 1.28 & 4.58 & 7.83 & 7.62 & 12.0 \\
\hline 3.00 & 2.57 & 1.25 & 13.1 & 8.46 & 0.75 & 8.25 \\
\hline 3.50 & 6.20 & 0.93 & 16.6 & 2.84 & 1.38 & 9.59 \\
\hline 4.00 & 3.92 & 0.97 & 18.0 & 1.32 & 2.44 & 29.2 \\
\hline 4.50 & 5.68 & 1.81 & 4.88 & 4.84 & 0.64 & 2.92 \\
\hline 5.00 & 3.60 & 0.66 & 10.3 & 3.44 & 1.38 & 17.9 \\
\hline$\% \mathrm{CV}_{\text {mean }}$ & 8.03 & 4.01 & 6.94 & 9.16 & 5.38 & 8.02 \\
\hline
\end{tabular}


Table 3 Comparison of the proposed (TMB) and commercial (DPD) methods at $t 0 \mathrm{~s}$. The analytical parameters have been obtained on three chlorine concentration ranges by using the piecewise linear fitting implemented in the Originlab software (ESM Fig. S1)

Calibration curve: $A_{\lambda \max }=A_{\lambda \max }^{0}+m \times\left[\mathrm{Cl}_{2}\right] ; A_{\lambda \max }^{0}$ is the intercept at $\left[\mathrm{Cl}_{2}\right]=0$, and $m$ is the slope

\begin{tabular}{|c|c|c|c|c|c|c|c|}
\hline \multirow[b]{2}{*}[\mathrm{Cl}_{2}]{$\left(\mathrm{mg} \mathrm{L}^{-1}\right)$} & \multirow[b]{2}{*}{ Analytical parameters } & \multicolumn{4}{|l|}{ TMB } & \multicolumn{2}{|l|}{ DPD } \\
\hline & & \multicolumn{2}{|c|}{$\lambda_{\max } 450 \mathrm{~nm}$ (yellow) } & \multicolumn{2}{|c|}{$\lambda_{\max } 655 \mathrm{~nm}$ (blue) } & \multicolumn{2}{|c|}{$\lambda_{\max } 555 \mathrm{~nm}$ (magenta) } \\
\hline \multirow[t]{4}{*}{$0.00-1.50$} & $A_{\lambda \max }^{0}$ & $0.03 \pm 0.02$ & $0.03 \pm 0.01$ & $0.05 \pm 0.01$ & $0.04 \pm 0.01$ & $0.08 \pm 0.01$ & $0.10 \pm 0.02$ \\
\hline & $\mathrm{m}\left(\mathrm{mg}^{-1} \mathrm{~L}\right)$ & $0.12 \pm 0.01$ & $0.08 \pm 0.02$ & $0.15 \pm 0.01$ & $0.17 \pm 0.01$ & $0.11 \pm 0.01$ & $0.11 \pm 0.03$ \\
\hline & $\% \mathrm{CV}_{\text {mean }}(n=4)$ & 8.08 & 9.62 & 2.79 & 3.00 & 11.47 & 14.64 \\
\hline & $\operatorname{LOD}\left(\mathrm{mg} \mathrm{L}^{-1}\right)$ & 0.05 & 0.11 & 0.04 & 0.02 & 0.13 & 0.42 \\
\hline \multirow[t]{3}{*}{$1.50-3.00$} & $A_{\lambda \max }^{0}$ & $-0.87 \pm 0.07$ & $-1.01 \pm 0.06$ & $0.48 \pm 0.02$ & $0.53 \pm 0.02$ & $0.05 \pm 0.03$ & $0.07 \pm 0.07$ \\
\hline & $\mathrm{m}\left(\mathrm{mg}^{-1} \mathrm{~L}\right)$ & $0.71 \pm 0.04$ & $0.77 \pm 0.03$ & $-0.14 \pm 0.01$ & $-0.16 \pm 0.01$ & $0.13 \pm 0.01$ & $0.13 \pm 0.03$ \\
\hline & $\% \mathrm{CV}_{\text {mean }}(n=4)$ & 0.95 & 3.59 & 5.06 & 6.05 & 7.63 & 8.60 \\
\hline \multirow[t]{3}{*}{$3.00-5.00$} & $A_{\lambda \max }^{0}$ & $1.46 \pm 0.19$ & $1.48 \pm 0.12$ & $0.11 \pm 0.05$ & $0.10 \pm 0.04$ & $0.17 \pm 0.03$ & $0.16 \pm 0.09$ \\
\hline & $m\left(\mathrm{mg}^{-1} \mathrm{~L}\right)$ & $-0.06 \pm 0.05$ & $-0.05 \pm 0.03$ & $-0.01 \pm 0.01$ & $-0.01 \pm 0.01$ & $0.09 \pm 0.01$ & $0.10 \pm 0.22$ \\
\hline & $\% \mathrm{CV}_{\text {mean }}(n=4)$ & 1.12 & 1.32 & 12.57 & 9.48 & 4.40 & 4.18 \\
\hline$R^{2}$ & & 0.99 & 0.99 & 0.98 & 0.98 & 1.00 & 0.98 \\
\hline
\end{tabular}

the blue product with a bell-shaped trend symmetrical about the midpoint corresponding to $0.50 \mathrm{~mol}$ chlorine/mol of TMB, i.e., $1.50 \mathrm{mg} \mathrm{L}^{-1}$ (Fig. 4c), as theoretically expected and previously shown for another oxidant system [15]. The yellow diimine absorbance $\left(\lambda_{\max } 450 \mathrm{~nm}\right)$ reaches the maximum when the oxidant concentration is equimolar with TMB, i.e., $3.00 \mathrm{mg} \mathrm{L}^{-1}$ of $\mathrm{Cl}_{2}$ chosen as maximum safe concentration for active chlorine in water, whereas at same chlorine concentration the blue color contribution from charge-transfer complex returns to the minimum level and the green color disappears from the plate with it (Fig. 4a and b). Conversely, the absorbance of DPD solutions recorded at $555 \mathrm{~nm}$ (magenta) shows a monotone increase with chlorine concentration, as expected (Fig. 4c and d), presenting also a reproducibility worse than TMB (Table 2). Finally, in agreement with previous studies describing the better precision, sensitivity, and safety of TMB over the other reagents used for colorimetric analysis of chlorine [21,22], here, we report a comparison at $t$ $0 \mathrm{~s}$ of the proposed method based on TMB, and commercial method based on DPD. The analytical parameters have been obtained on three chlorine concentration ranges by using the piecewise linear fitting implemented in the Originlab software

Table 4 Comparison of up-to-date colorimetric methods for determination of free chlorine in tap water and swimming pool water samples

\begin{tabular}{|c|c|c|c|c|}
\hline Reference & Dou et al. [9] & Schwenke et al. [10] & Commercial kit $^{\mathrm{a}}$ & This work \\
\hline Device & Smartphone-based colorimeter & Barcode color reader & Colorimeter or naked eye $\mathrm{e}^{\mathrm{b}}$ & Colorimeter or naked eye $\mathrm{e}^{\mathrm{b}}$ \\
\hline Stained substrate & None & 3D-printed material & None & None \\
\hline $\operatorname{LOD}\left(\mathrm{mg} \mathrm{L}^{-1}\right)$ & 0.016 & 0.05 & 0.42 & 0.02 \\
\hline Working range $\left(\mathrm{mg} \mathrm{L}^{-1}\right)$ & $0.00-1.00$ & $0.00-1.00$ & $0.00-5.00$ & $0.00-5.00$ \\
\hline Indicator & DPD & DPD & DPD & TMB \\
\hline Color range & Magenta & Magenta & Magenta & Blue-Green-Yellow \\
\hline Masking agent & EDTA & None & None & Phosphate salts \\
\hline Redox selectivity & Low $^{c}$ & Low $^{\mathrm{c}, \mathrm{d}}$ & Low $^{\mathrm{c}}$ & $\operatorname{High}^{\mathrm{c}}$ \\
\hline Sample manipulation & Yes (Dilution) ${ }^{\mathrm{e}}$ & Yes (Dilution) ${ }^{\mathrm{e}}$ & None & None \\
\hline
\end{tabular}

${ }^{a}$ DPD1 free chlorine test kit used in this work (see Table 3)

${ }^{\mathrm{b}}$ By using a monochromatic reference scale for DPD and multi-color reference scale for TMB

${ }^{c}$ As an example, DPD is readily oxidized by $\mathrm{H}_{2} \mathrm{O}_{2}$ whereas TMB requires the presence of peroxidases for efficient oxidation by $\mathrm{H}_{2} \mathrm{O}_{2}$ [15]. For ion tolerance of TMB oxidation by chlorine please see ESM Table $\mathrm{S} 1$ and reference herein

${ }^{\mathrm{d}}$ Several printed substrates are reported to be redox sensitive [10]

${ }^{\mathrm{e}}$ To cover the range recommended by international health agencies for tap water and swimming pools [3, 4] 
(ESM Fig. S1). In detail, Table 3 shows the best detection limit (LOD) for the linear fitting of TMB blue color development $\left(\lambda_{\max } 655 \mathrm{~nm}\right)$ for lower chlorine concentrations $(0.00$ $1.50 \mathrm{mg} \mathrm{L}^{-1}$ ) in $\mathrm{H}_{2} \mathrm{O}$ and tap water. Moreover, the sensitivity represented by the slope $(m)$ of the calibration curve and the reproducibility reported as $\% \mathrm{CV}_{\text {mean }}$ appear both superior for TMB (both at $\lambda_{\max } 655 \mathrm{~nm}$ and $450 \mathrm{~nm}$ ) over DPD method, in $\mathrm{H}_{2} \mathrm{O}$ and tap water, within the working range for chlorine determination $\left(0.00-3.00 \mathrm{mg} \mathrm{L}^{-1}\right)$. Notably, although the improvement of the current detection limit of chlorine concentration in water is out of the scope of this paper, our LOD in tap water $\left(0.02 \mathrm{mg} \mathrm{L}^{-1}\right)$ is close to, or below, the values recently reported for other up-to-date and smart colorimetric methods based on DPD (Table 4) [9, 10].

\section{Conclusion}

This work contributes to the field of the colorimetric determination of free chlorine in water by using TMB, which is the safer chromogenic substitute of benzidine in clinical chemistry assays, already shown to have a precision and sensitivity higher than other common colorimetric methods and offering the further advantage of hue modulation upon oxidation. The latter feature of TMB solutions have been exploited here for spectroscopic detection of chlorine in water, and even nakedeye sensing appears possible through the recognition of typical color of each oxidation stage of TMB in diphosphatebased buffer at $\mathrm{pH} 4.5$, which is also able to mask potential redox active ions, e.g., $\mathrm{Fe}(\mathrm{III})$, commonly present in drinking water and swimming pools. The key novelty of this work lies in the appropriate setting of reaction conditions, showing for the first time that it is possible to finely tune the TMB colors change to cover exactly the range of chlorine concentration recommended by international health agencies for treatment of drinking water and swimming pools. The assay relies on the simple tuning of TMB final concentration to be equimolar to chlorine concentration value with limited potential health effects from long-term exposure. Therefore, obtaining a multicolorimetric indicator of chlorine in water working between minimum value, to achieve effective disinfection, and maximum health guideline value, to avoid irritations or discomfort. Consequently, the improvement of the current detection limit of chlorine concentration in water, well below guideline concentrations, is clearly out of the scope of this paper. In detail, TMB solutions produce a yellow color at the maximum safe concentration of chlorine, a green color at intermediate and recommended optimal chlorine values, and a blue color at the prescribed lower end concentration of chlorine in water. The method has been also successfully applied in tap water and appears superior to a commercial test kit for visual sensing and quantification of chlorine in swimming pools that are instead based on monochromatic chromophores like DPD. Finally, this analytical method could offer a practical tool to test home-made sanitizing solutions, and their "shelf life," necessarily prepared by serial dilution of household chlorine bleach during supply shortage for public health emergency events such as pandemic influenza, as we did here to prepare a stock solution from concentrated chlorine bleach bottle, pointing out the significance of this work in human healthcare. A different modulation of TMB assay for a direct measure of higher chlorine concentration will be the subject of future work.

Funding This study was supported by a grant for the scientific program PLABAN (grant D53D16002290009) from the Regione Toscana.

\section{Compliance with ethical standards}

Conflict of interest The authors declare that they have no conflict of interest.

\section{References}

1. Bruchet A, Duguet JP. Role of oxidants and disinfectants on the removal, masking and generation of tastes and odours. Water Sci Technol. 2004. https://doi.org/10.2166/wst.2004.0589.

2. Deborde M, von Gunten URS. Reactions of chlorine with inorganic and organic compounds during water treatment-kinetics and mechanisms: a critical review. Water Res. 2008. https://doi.org/10.1016/ j.watres.2007.07.025.

3. EPA, United States Environmental Protection Agency, Office of Ground Water and Drinking Water. National Primary Drinking Water Regulations; https://www.epa.gov/ground-water-anddrinking-water/national-primary-drinking-water-regulations. Accessed 03 July 2020.

4. WHO, World Health Organization. In: Guidelines for drinkingwater quality. 4th ed. 2011; https://www.who.int/water sanitation_health/publications/gdwq4-with-add1-chapters/en/. Accessed 03 July 2020.

5. Nagy G, Nagy L. Halogens. In: Nollet LM, De Gelder LS, editors. Handbook of water analysis. CRC press; 2000. pp. 189-199.

6. Rice EW, Baird RB, Eaton AD, editors. APHA, American Public Health Association Publisher, Standard methods for the examination of water and wastewater 23rd edition, Part 4500-Cl, Chlorine (Residual) 4-61-4-74. 2017.

7. O'Riordan A, O'Sullivan B, Lovera P, Seymour I, Rohan J. Electrochemical Detection of free-chlorine in water samples facilitated by in-situ ph control using interdigitated microelectrodes. ChemRxiv. 2020; Preprint: https://doi.org/10.26434/chemrxiv. 11898126.v1

8. Nandi S, Shyam B. A diamino functionalized metal-organic framework for fluorometric recognition of free chlorine in environmental water samples. Microporous Mesoporous Mater. 2020. https://doi. org/10.1016/j.micromeso.2020.110116.

9. Dou J, Shang J, Kang Q, Shen D. Field analysis free chlorine in water samples by a smartphone-based colorimetric device with improved sensitivity and accuracy. Microchem J. 2019. https://doi. org/10.1016/j.microc.2019.104200.

10. Schwenke KU, Spiehl D, Krauße M, et al. Analysis of free chlorine in aqueous solution at very low concentration with lateral flow tests. Sci Rep. 2019. https://doi.org/10.1038/s41598-019-53687-0. 
11. Holland VR, Saunders BC, Rose FL, Walpole AL. A safer substitute for benzidine in the detection of blood. Tetrahedron. 1974. https://doi.org/10.1016/S0040-4020(01)97504-0.

12. Goda Y, Kobayashi A, Fujimoto S, Toyoda Y, Miyagawa KI, Ike $\mathrm{M}$, et al. Development of enzyme-linked immunosorbent assay for detection of alkylphenol polyethoxylates and their biodegradation products. Water Res. 2004. https://doi.org/10.1016/j.watres.2004. 07.030 .

13. Hintemann T, Schneider C, Schöler HF, Schneider RJ. Field study using two immunoassays for the determination of estradiol and ethinylestradiol in the aquatic environment. Water Res. 2006. https://doi.org/10.1016/j.watres.2006.04.028.

14. Wu L, Li G, Xu X, Zhu L, Huang R, Chen X. Application of nanoELISA in food analysis: recent advances and challenges. Trends Anal Chem. 2019. https://doi.org/10.1016/j.trac.2019.02.002.

15. Josephy PD, Eling T, Mason RP. The horseradish peroxidasecatalyzed oxidation of 3,5,3',5'-tetramethylbenzidine. Free radical and charge-transfer complex intermediates. J Biol Chem. 1982;257: 3669-75.

16. Bally RA, Gribnau TCJ. Some aspects of the chromogen 3,3',5,5'tetramethylbenzidine as hydrogen donor in a horseradish peroxidase assay. Clin Chem Lab Med. 1989. https://doi.org/10.1515/ cclm.1989.27.10.791.

17. Awano $\mathrm{H}$, Ohigashi $\mathrm{H}$. Absorption spectra of the cationic radical salt of 3,3',5,5'-tetramethylbenzidine in acetonitrile. Bull Chem Soc Jpn. 1990. https://doi.org/10.1246/bcsj.63.2101.

18. Misono Y, Ohkata Y, Morikawa T, Itoh K. Resonance Raman and absorption spectroscopic studies on the electrochemical oxidation processes of 3,3',5,5'-tetramethylbenzidine. J Electroanal Chem. 1997. https://doi.org/10.1016/S0022-0728(97)00305-7.

19. Li B, Du Y, Li T, Dong S. Investigation of $3,3^{\prime}, 5,5^{\prime}-$ tetramethylbenzidine as colorimetric substrate for a peroxidatic DNAzyme. Anal Chim Acta. 2009. https://doi.org/10.1016/j.aca. 2009.09.009.

20. Drozd M, Pietrzak M, Parzuchowski PG, Malinowska E. Pitfalls and capabilities of various hydrogen donors in evaluation of peroxidase-like activity of gold nanoparticles. Anal Bioanal Chem. 2016. https://doi.org/10.1007/s00216-016-9976-z.

21. Serrat FB. Colorimetric method for determination of chlorine with 3,3',5,5'-tetramethylbenzidine. Talanta. 1994. https://doi.org/10. 1016/0039-9140(94)00184-7.
22. Serrat FB, Morell GB, Polo DR. Comparison of methods and kits for colorimetric determination of residual chlorine in water. $\mathrm{J}$ AOAC Int. 1997;80:1117-21.

23. Mesquita RB, Noronha MLF, Pereira AI, Santos AC, Torres AF, Cerdà V, et al. Use of tetramethylbenzidine for the spectrophotometric sequential injection determination of free chlorine in waters. Talanta. 2007. https://doi.org/10.1016/j.talanta.2007.01.010.

24. Guo Y, Ma Q, Cao F, Zhao Q, Ji X. Colorimetric detection of hypochlorite in tap water based on the oxidation of $3,3^{\prime}, 5,5^{\prime}$ tetramethyl benzidine. Anal Methods. 2015. https://doi.org/10. 1039/c5ay00735f.

25. Zhang J, Yang X. A simple yet effective chromogenic reagent for the rapid estimation of bromate and hypochlorite in drinking water. Analyst. 2013. https://doi.org/10.1039/c2an36287b.

26. Yamaoka H, Nakayama-Imaohji H, Horiuchi I, Yamasaki H, Nagao T, Fujita Y, et al. Tetramethylbenzidine method for monitoring the free available chlorine and microbicidal activity of chlorite-based sanitizers under organic-matter-rich environments. Lett Appl Microbiol. 2016. https://doi.org/10.1111/lam.12506.

27. Andrews PC, Krinsky NI. Quantitative determination of myeloperoxidase using tetramethylbenzidine as substrate. Anal Biochem. 1982. https://doi.org/10.1016/0003-2697(82)90185-3.

28. Freitas M, Lima JL, Fernandes E. Optical probes for detection and quantification of neutrophils' oxidative burst. A review. Anal Chim Acta. 2009. https://doi.org/10.1016/j.aca.2009.06.063.

29. Kettle AJ, Albrett AM, Chapman AL, Dickerhof N, Forbes LV, Khalilova I, et al. Measuring chlorine bleach in biology and medicine. Biochim Biophys Acta. 2014. https://doi.org/10.1016/j. bbagen.2013.07.004.

30. Palladino P, Torrini F, Scarano S, Minunni M. Colorimetric analysis of the early oxidation of dopamine by hypochlorous acid as preliminary screening tool for chemical determinants of neuronal oxidative stress. J Pharm Biomed Anal. 2020. https://doi.org/10. 1016/j.jpba.2019.113016.

31. Feng Y, Smith DW, Bolton JR. Photolysis of aqueous free chlorine species ( $\mathrm{HOCl}$ and $\mathrm{OCl}$ ) with $254 \mathrm{~nm}$ ultraviolet light. J Environ Eng Sci. 2007. https://doi.org/10.1139/s06-052.

Publisher's note Springer Nature remains neutral with regard to jurisdictional claims in published maps and institutional affiliations. 